\title{
REALIZATIONS OF THE COMPLEX NILPOTENT LIE ALGEBRAS WITH SMALL SECOND DERIVED QUOTIENT*
}

\author{
ERNIE STITZINGER ${ }^{\dagger}$ AND LAURIE ZACK Z $^{\ddagger}$
}

\begin{abstract}
The fourteen complex nilpotent Lie algebras with a small derived quotient are realized here using $7 \times 7$ matrices.
\end{abstract}

Key words. Nilpotent Lie algebra, Small second derived quotient.

AMS subject classifications. 17B30.

1. Introduction. The Lie algebra analogue to the theory of p-groups with small second derived quotient studied by Schneider [1] was given by Zack [2]. Similar to the group case, she found that such an algebra is the central direct sum of ideals $\mathrm{K}$ and $\mathrm{U}$, and the structures of both $\mathrm{K}$ and $\mathrm{U}$ were found. For complex nilpotent Lie algebras with a small second derived quotient, it was found that $U$ is the direct sum of a generalized Heisenberg algebra and an abelian Lie algebra, and that $\mathrm{K}$ is one of fourteen algebras. For each of these algebras, a multiplication table was found having a simple form, which we will call the canonical multiplication for the algebra. The fourteen algebras divide evenly into two types such that each algebra of the first type corresponds directly to an algebra of the second type. Here we realize these algebras as matrices and the realizations are satisfying in that slight variations in the generating matrices lead to all the canonical representatives for a given type. For this paper, all matrices are 7 by 7 and the Lie algebra brackets that follow are for left normed multiplication.

Let $L$ be a complex nilpotent Lie algebra with $\operatorname{dim}\left(L^{\prime} / L^{\prime \prime}\right)=3$ and $L^{\prime \prime} \neq 0$. Then $L$ contains a six dimensional ideal $\mathrm{H}$ with basis $\{\mathrm{a}, \mathrm{b},[\mathrm{a}, \mathrm{b}],[\mathrm{a}, \mathrm{b}, \mathrm{a}],[\mathrm{a}, \mathrm{b}, \mathrm{a}, \mathrm{a}],[\mathrm{a}, \mathrm{b}, \mathrm{a}, \mathrm{a}, \mathrm{b}]\}$, multiplication $[\mathrm{a}, \mathrm{b}, \mathrm{a}, \mathrm{b}]=0,[\mathrm{a}, \mathrm{b}, \mathrm{a}, \mathrm{a}, \mathrm{a}]=0$, and either $[\mathrm{a}, \mathrm{b}, \mathrm{b}]=0$ or $[\mathrm{a}, \mathrm{b}, \mathrm{b}]=[\mathrm{a}, \mathrm{b}, \mathrm{a}, \mathrm{a}]$.

These two possibilities for [a,b,b] will be called type I and type II, respectively. Then, for each type, $\mathrm{K}$ is one of seven classes, obtained by using $\mathrm{H}$ and $0,1,2$ or 3 additional generators. For simplicity, let $\mathrm{y}=[\mathrm{a}, \mathrm{b}, \mathrm{a}, \mathrm{a}]$ and $\mathrm{z}=[\mathrm{a}, \mathrm{b}, \mathrm{a}, \mathrm{a}, \mathrm{b}]$. It was shown

\footnotetext{
${ }^{*}$ Received by the editors January 22, 2009. Accepted for publication August 7, 2009. Handling Editor: Robert Guralnick.

${ }^{\dagger}$ Department of Mathematics, North Carolina State University, Raleigh, North Carolina 27695, USA (stitz@ncsu.edu).

${ }^{\ddagger}$ Department of Mathematics, High Point University, High Point, NC 27262, USA (lzack@highpoint.edu).
} 
that the seven algebras of each type are as follows [2]:

1. $\mathrm{H}$

2. $<\mathrm{H}, \mathrm{u}>$ with $[\mathrm{u}, \mathrm{a}]=\mathrm{z}$ and $[\mathrm{u}, \mathrm{b}]=0$.

3. $<\mathrm{H}, \mathrm{u}>$ with $[\mathrm{u}, \mathrm{a}]=0$ and $[\mathrm{u}, \mathrm{b}]=\mathrm{y}$.

4. $<\mathrm{H}, \mathrm{u}>$ with $[\mathrm{u}, \mathrm{a}]=\mathrm{z}$ and $[\mathrm{u}, \mathrm{b}]=\mathrm{y}$.

5. $<\mathrm{H}, \mathrm{u}_{1}, \mathrm{u}_{2}>$ with $\left[\mathrm{u}_{1}, \mathrm{a}\right]=\mathrm{z},\left[\mathrm{u}_{1}, \mathrm{~b}\right]=0,\left[\mathrm{u}_{2}, \mathrm{a}\right]=0,\left[\mathrm{u}_{2}, \mathrm{~b}\right]=\mathrm{y}$ and $\left[\mathrm{u}_{1}, \mathrm{u}_{2}\right]=0$.

6. $<\mathrm{H}, \mathrm{u}_{1}, \mathrm{u}_{2}>$ with $\left[\mathrm{u}_{1}, \mathrm{a}\right]=\mathrm{z},\left[\mathrm{u}_{1}, \mathrm{~b}\right]=0,\left[\mathrm{u}_{2}, \mathrm{a}\right]=0,\left[\mathrm{u}_{2}, \mathrm{~b}\right]=\mathrm{y}$ and $\left[\mathrm{u}_{1}, \mathrm{u}_{2}\right]=\mathrm{z}$.

7. $<\mathrm{H}, \mathrm{u}_{1}, \mathrm{u}_{2}, \mathrm{u}_{3}>$ with $\left[\mathrm{u}_{1}, \mathrm{a}\right]=\mathrm{z},\left[\mathrm{u}_{1}, \mathrm{~b}\right]=0,\left[\mathrm{u}_{2}, \mathrm{a}\right]=0,\left[\mathrm{u}_{2}, \mathrm{~b}\right]=\mathrm{y},\left[\mathrm{u}_{3}, \mathrm{a}\right]=0$, $\left[\mathrm{u}_{3}, \mathrm{~b}\right]=0$ and $\left[\mathrm{u}_{1}, \mathrm{u}_{2}\right]=0,\left[\mathrm{u}_{1}, \mathrm{u}_{3}\right]=0$ and $\left[\mathrm{u}_{2}, \mathrm{u}_{3}\right]=\mathrm{z}$.

2. Realizations. The following are the realizations of the algebras for types I and II.

Type I. Let $\mathrm{a}=E_{(1,2)}+E_{(2,3)}+E_{(3,5)}+E_{(5,6)}-E_{(6,7)}$ and $\mathrm{b}=E_{(1,2)}+E_{(6,7)}$ where $E_{(i, j)}$ are matrix units. Then let $\mathrm{v}=E_{(2,7)}+E_{(1,6)}$ and $\mathrm{w}=E_{(2,6)}-E_{(3,7)}+E_{(1,5)}$

Short calculations verify that the following list gives a set of generators corresponding to each of the algebras of type I.

1. $\mathrm{a}, \mathrm{b}$

2. $a, b, u=v$

3. $a, b, u=w$

4. $\mathrm{a}, \mathrm{b}, \mathrm{u}=\mathrm{v}+\mathrm{w}$

5. a,b, $\mathrm{u}_{1}=\mathrm{v}, \mathrm{u}_{2}=\mathrm{w}$

6. a,b, $\mathrm{u}_{1}=\mathrm{v}+2 E_{(4,7)}, \mathrm{u}_{2}=\mathrm{w}+E_{(1,4)}$

7. a,b, $\mathrm{u}_{1}=\mathrm{v}, \mathrm{u}_{2}=\mathrm{w}+E_{(1,4)}, \mathrm{u}_{3}=-2 E_{(4,7)}$.

Type II. Let $\mathrm{a}=E_{(1,2)}+E_{(4,5)}+E_{(3,5)}+E_{(5,6)}$ and $\mathrm{b}=E_{(2,3)}+E_{(6,7)}+3 E_{(3,6)}$ and then let $\mathrm{v}=-3 E_{(2,7)}$ and $\mathrm{w}=E_{(1,3)}-E_{(1,4)}$.

As for Type I, the following are the generators corresponding to each of the seven type II algebras.

1. $a, b$

2. $a, b, u=v$

3. $a, b, u=w$

4. $a, b, u=v+w$

5. a,b, $\mathrm{u}_{1}=\mathrm{v}, \mathrm{u}_{2}=\mathrm{w}$

6. a,b, $\mathrm{u}_{1}=\mathrm{v}+3 E_{(4,7)}, \mathrm{u}_{2}=\mathrm{w}$

7. a,b, $\mathrm{u}_{1}=\mathrm{v}, \mathrm{u}_{2}=\mathrm{w}, \mathrm{u}_{3}=-3 E_{(4,7)}$. 
Electronic Journal of Linear Algebra ISSN 1081-3810

A publication of the International Linear Algebra Society

ELA

Realizations of the Complex Nilpotent Lie Algebras

\section{REFERENCES}

[1] Csaba Schneider. Groups of prime-power order with a small second derived quotient. Journal of Algebra, 266:539-551, 2003.

[2] Laurie Zack. Nilpotent Lie algebras with a small second derived quotient. Communications in Algebra, 36:4607-4619, 2008. 